\title{
El retablo jerezano en el último cuarto del siglo XVII: Fernando Delgado y Bernardo Martín de la Guardia
}

\author{
José Manuel Moreno Arana \\ Universidad de Sevilla \\ morenoarana@gmail.com
}

RESUMEN: Este artículo es una aproximación a la vida y la obra de los hermanos Fernando Delgado y Bernardo Martín de la Guardia, artistas activos en Jerez de la Frontera durante el último cuarto del siglo XVII, que dirigieron uno de los talleres de retablos más importantes de la ciudad en esa época. Tras estudiar el contexto artístico en el que trabajan, se aportan múltiples datos inéditos que permiten reconstruir sus biografías. Asimismo se hace un repaso completo de su producción, identificando los escasos retablos documentados que han llegado hasta nosotros, como los tres que realizaron para la iglesia del convento del Espíritu Santo de Jerez, de los que se aportan fotografías del estado que presentaban antes de ser desmontados con motivo del reciente cierre que ha sufrido este cenobio.

PALABRAS CLAVE: Retablo, Barroco, Arte del siglo XVII, Jerez de la Frontera, Fernando Delgado, Bernardo Martín de la Guardia.

\section{The Altarpiece in Jerez de la Frontera during the last Quarter of the $17^{\text {th }}$ Century: Fernando Delgado and Bernardo Martín de la Guardia}

ABSTRACT: This paper is an approach to the life and work of the Fernando Delgado and Bernardo Martin de la Guardia brothers, artists working in Jerez de la Frontera during the last quarter of the $17^{\text {th }}$ century. They directed one of the most important workshops of altarpiece in the city at that time. After studying the artistic context in which they work, we publish new data which allow to reconstruct their biographies. Moreover, a complete review of their production is done, identifying the few documented altarpieces which have survived, such as the three made for the Convent of the Holy Spirit in Jerez. We make public photographs taken before the recent closure of this monastery.

KEY WORDS: Altarpiece, Baroque, $17^{\text {th }}$ Century Art, Jerez de la Frontera, Fernando Delgado, Bernardo Martín de la Guardia.

Recibido: 14 de abril de 2015 / Aceptado: 16 de junio de 2015.

Recientemente ha sido publicada una monografía sobre El retablo en Jerez de la Frontera durante el siglo XVIII donde se dan algunas notas sobre los antecedentes en el XVII de la etapa salomónica que experimenta la retablística jerezana a principios del setecientos ${ }^{1}$. Dentro de este periodo despunta el sevillano Francisco Antonio de Soto, artista cuya actividad une ambos siglos.

Por las limitaciones cronológicas del referido libro han quedado fuera de él los retablistas Fernando Delgado y Bernardo Martín de la Guardia, dos hermanos que constituyeron un obrador que llegaría a ser, junto al de Soto, el más relevante en Jerez a lo largo del último cuarto del siglo XVII. Así se ha constatado por la documentación que ha ido apareciendo en los últimos años. En este sentido, imprescindibles para abordar sus figuras son las investigaciones de Jácome González y Antón Portillo, autores que han sacado a la luz una gran cantidad de noticias sobre su amplia producción². Sin embargo, hasta ahora no ha habido ningún intento de estudiar sus biografías. Tampoco se ha profundizado en sus obras pues, aunque lamentablemente hayan desaparecido en su mayoría, no ha sido identificado con claridad ninguno de sus trabajos con

MORENO ARANA, José Manuel: "El retablo jerezano en el último cuarto del siglo XVII: Fernando Delgado y Bernardo Martín de la Guardia», Boletín de Arte, n. ${ }^{\circ}$ 36, Departamento de Historia del Arte, Universidad de Málaga, 2015, pp. 125-135, ISSN: 0211-8483. 
piezas conservadas, aunque sí se cuenta con un par de sucintas atribuciones, planteadas por Pomar Rodil y Mariscal Rodríguez ${ }^{3}$.

Con el objetivo de procurar arrojar algo más de luz sobre estos artistas y sobre el retablo jerezano del seiscientos presentamos este artículo, en el que, tras un breve acercamiento al contexto artístico en el que se mueven, se ofrecen datos biográficos que permiten reconstruir sus trayectorias vitales. Igualmente, hemos ahondado en su obra documentada, lo que nos ha permitido localizar ciertas piezas que han llegado a nosotros y hacer una tentativa de reconstrucción de las formas estéticas desarrolladas por este taller.

\section{El contexto artístico: el retablo barroco jerezano del siglo XVII}

Frente a lo que ocurrirá en el siglo XVIII, durante el seiscientos el retablo en Jerez de la Frontera muestra una mayor dependencia exterior, principalmente de Sevilla y Cádiz. De hecho, será a obradores asentados en estas ciudades a los que la clientela jerezana acudirá para las piezas de mayor entidad. Ejemplos significativos son los retablos mayores de la parroquia de San Miguel y del monasterio de la Cartuja. En el primero es Juan Martínez Montañés quien se encarga de su arquitectura y parte de su escultura entre 1617 y 1641. En el segundo, lamentablemente destruido, es un maestro afincado en Cádiz, Alejandro de Saavedra, el que lo lleva a cabo de 1636 a 1637. Al respecto de este último retablo merece la pena recordar que fue pionero en el ámbito andaluz por el temprano uso que se hace en él de la columna salomónica ${ }^{4}$. Otra obra de cierta importancia, aunque sin alcanzar los niveles de los que acabamos de citar, es el retablo mayor del convento de la Merced, contratado en 1654 por Francisco Dionisio de Ribas 5 . Asimismo, nos quedan referencias a trabajos retablísticos, la mayoría desaparecidos, de maestros «secundarios" procedentes de ambos centros artísticos. Son los casos de Francisco de Villegas, escultor del círculo de Montañés que fue vecino de Cádiz y que en 1625 y 1650 ejecuta sendos altares para los conventos locales del Carmen y Santo Domingo, respectivamente ${ }^{6}$; Francisco Ramírez, un ensamblador sevillano poco conocido que concierta varios retablos entre 1663 y 16647, destacando el retablo del Dulce Nombre de Jesús de la igle- sia de Santo Domingo, que lo muestra en una línea estética cercana a la familia Ribas; o los retablistas instalados en Cádiz pero de procedencia hispalense Damián Machado, que se sabe que trabaja en la Cartuja en $1676^{\circ}$, y Juan González de Herrera, que se obliga en 1673 a hacer un retablo para la Virgen del Socorro de San Miguel y en 1694 un sagrario para la parroquia de San Marcos ${ }^{9}$. También llega de Sevilla el que puede considerarse el más destacado arquitecto de retablos activo en Jerez entre finales del XVII y principios del XVIII, Francisco Antonio de Soto, autor, entre otros, del último gran retablo del seiscientos en la ciudad, el mayor de Santo Domingo (h.1687-1690), donde manifiesta su formación en la órbita de Bernardo Simón de Pineda y Cristóbal de Guadix ${ }^{10}$.

Por tanto, desde la capital de la archidiócesis, de la que Jerez formaba parte en lo religioso, llegan no solo artistas y obras, sino también modelos estéticos, que serán asimilados por los ensambladores locales. Estos parecen moverse en este siglo en unas cotas algo más discretas que las que alcanzarán los maestros jerezanos del setecientos. Y no hablamos solo de una cuestión técnica. En estos años están ausentes los anhelos de ascenso social y el debate teórico en torno al carácter liberal del retablista que sí encontramos en fechas posteriores. Al contrario, personajes como Lorenzo de Vargas, los dos protagonistas de este artículo o José Rey ${ }^{11}$ se muestran ajenos a estas preocupaciones e incluso se autodenominan carpinteros en los documentos. En este sentido, se sabe que el propio Vargas llegó a ser hermano mayor de la cofradía de San José, vinculada al gremio de la carpintería de lo blanco, el cual parece vivir un periodo de esplendor y ejercer un mayor control por esta época, constándonos incluso la emisión de cartas de examen para el oficio de ensamblador, frente a la aparente libertad con la que ejercerán en Jerez su profesión los maestros dieciochescos ${ }^{12}$.

Aunque sería deseable un estudio más profundo, imposible dentro de los objetivos que nos hemos impuesto en la presente investigación, merece la pena que le dediquemos unas líneas a Lorenzo de Vargas, del que consta que desarrolló una importante actividad desde la década de los cincuenta del seiscientos hasta, al menos, $1682^{13}$. En diferentes escrituras y en los padrones parroquiales lo encontramos viviendo en la calle Larga desde los años centrales del siglo hasta $1685^{14}$. Contamos con datos sobre un buen 
número de retablos salidos de su taller, aunque la práctica totalidad de ellos han desaparecido. Curiosamente solo se han conservado dos en los que su intervención es difícil de aquilatar, ya que se limitó en ellos a terminar piezas ya iniciadas. Nos referimos al ya mencionado retablo del Dulce Nombre de Santo Domingo y a un antiguo retablo de la capilla de las Angustias, que parece hoy perdurar en la capilla de la Veracruz de Lebrija ${ }^{15}$. Ambos trabajos se fechan en 1665 y fueron dejados sin acabar por el referido Francisco Ramírez. Pese a todo ello, son obras muy diferentes entre sí, siendo el lebrijano más evolucionado pues se articula ya por columnas salomónicas y posee una decoración más menuda y abigarrada, en un sentido más próximo, sobre todo en el molduraje del entablamento, a lo que vemos en Delgado y De la Guardia. Por último, es interesante añadir que se ha demostrado que Vargas tuvo contactos con Juan González de Herrera, pues aparece como testigo en el contrato que firma este para hacer el retablo del Socorro de San Miguel ${ }^{16}$. Todo esto nos habla de una red de relaciones y de posibles influencias que quizás puedan explicar la personalidad estética del taller de los hermanos protagonistas de este artículo.

\section{Datos biográficos}

Fernando Delgado y Bernardo Martín de la Guardia debieron de nacer en torno a los años centrales del siglo XVII, aunque ignoramos las fechas exactas de sus respectivos nacimientos. Sí parece claro que eran jerezanos. Al menos, es lo que sabemos de Bernardo. El dato figura en su partida matrimonial, donde asimismo se constata su condición de «hijo de padres no conocidos» ${ }^{17}$, circunstancia que habría que suponer también para su hermano Fernando ${ }^{18}$. La primera referencia a ellos que hemos localizado se encuentra en el padrón parroquial de San Miguel de 1659. Figuran viviendo en la casa de una viuda llamada Francisca de Vargas, situada en la calle Larga ${ }^{19}$.

Sus formaciones artísticas son una incógnita, si bien resulta lógico que se efectuaran en Jerez y muy probablemente junto a Lorenzo de Vargas. Es llamativo que este maestro, además de ser el principal retablista local del momento, residiera en la misma calle Larga. Además es revelador que aparezca como testigo en la boda de Bernardo. Asi- mismo, cabe la posibilidad de que la mencionada Francisca de Vargas fuera familiar suya.

Por otro lado, no sabemos qué tipo de relación pudieron tener estos hermanos con la familia Martín de la Guardia, afincada en la cercana calle Naranjas ${ }^{20}$. Uno de sus miembros, Pedro Martín de la Guardia, parece que se dedicó a la venta de madera y, de hecho, lo encontramos en una escritura abasteciendo de este material al propio Lorenzo de $\operatorname{Vargas}^{21}$.

Fernando y Bernardo permanecieron avecindados durante toda su vida en la estratégica calle Larga ${ }^{22}$, donde mantuvieron abierto su taller, al igual que otros retablistas del Jerez del momento, como Francisco Antonio de Soto o el propio Vargas. Bernardo se casa el 19 de febrero de 1679 con Manuela Francisca de Luna ${ }^{23}$. Por esta unión recibió de su esposa una sustanciosa dote de 300 ducados «en tributos y dineros y bienes muebles de ajuar y ropa». Tuvieron cuatro hijas: Juana María, Beatriz, Rosa y Luciana Josefa $^{24}$. Bernardo fallecería en 1694. El 30 de abril de ese año dicta su testamento. A través de él manda entonces ser enterrado en el convento de San Francisco, en concreto en la capilla de Jesús Nazareno, por lo que cabe suponer que fue hermano de esa cofradía. Como propiedades dejó la mitad de la casa de su morada, cuya posesión compartió con su hermano, una serie de tributos y los «bienes muebles de omenage de casa». Como albaceas nombra a su mujer y a su hermano y como herederas a sus hijas. Aparecen como testigos dos miembros del clero jerezano, con el que debió de tener buenas y estrechas relaciones, el presbítero Esteban de Torres y el clérigo de menores órdenes Juan de Molina ${ }^{25}$. Recibió sepultura el 2 de mayo siguiente ${ }^{26}$.

Fernando Delgado, aunque permaneció soltero, fue de los dos hermanos el que gozaría de una posición más preeminente dentro del taller familiar. Así lo probaría el hecho de que otorgue a veces contratos en solitario. Es asimismo interesante que se le asigne en 1677 para hacer el diseño de unas andas de plata para la cofradía del Dulce Nombre, lo que da a entender ciertas dotes como tracista ${ }^{27}$. Tras la muerte de Bernardo, Fernando Delgado continuó viviendo en la casa familiar hasta su muerte, que se produciría en $1708^{28}$. Por tanto, seguiría trabajando entrado el siglo XVIII, si bien por ahora no se ha localizado ninguna obra suya de estos últimos años. En este sentido, sabemos por su tes- 
tamento, otorgado el 1 de octubre de 1708, que entre sus posesiones se encontraban, además de su vivienda, las herramientas de su "ofisio de carpintero", lo que parece indicar que se mantuvo activo hasta al final de su vida. En este documento manda ser enterrado en la iglesia parroquial de San Miguel y nombra como albacea y heredera a su cuñada Manuela de Luna29.

\section{Producción artística}

A lo largo de su trayectoria Delgado y De la Guardia combinaron la construcción de retablos con obras de talla e incluso de carpintería de lo blanco. De hecho, como simples carpinteros se alude a ellos en no pocos contratos. En esta línea de trabajos, aportamos la referencia a una obra para el convento de San Cristóbal, fechada en 1689. El documento, parcialmente ilegible, habla de hacer «vigas tavicadas retocadas y moldadas y alfaxias de quarton», apuntando que todo tenía que ser «muy curioso, primoroso y aseado». Debía realizarse a contento de Fernando Jaime Cordero, canónigo magistral, y costaría 4 ducados de vellón, siendo la madera a costa del convento ${ }^{30}$. Por otro lado, se cuenta con noticias de encargos de «urnas» o andas para las cofradías de la Vera Cruz (1682) y de San Antonio Abad (1695) ${ }^{31}$. En la escritura de obligación de la última, emitida ya muerto Bernardo, encontramos un nuevo artista colaborando con Delgado, Pedro Mateos. Por los padrones parroquiales de 1684 y 1685 se sabe que Mateos residió en la casa de Delgado y De la Guardia, por lo que hay que suponer que fue oficial de su taller. Es nombrado como maestro escultor y lo volvemos a ver también el 22 de mayo de 1695 contratando junto a Fernando un túmulo para la cofradía del Santo Entierro, una inédita y singular pieza hecha para la ceremonia del Descendimiento que esta hermandad representaba cada Viernes Santo en el Arenalejo de Santiago. La escritura afirma que se tallaría en pino de Flandes, siguiendo un dibujo hecho para este fin y por el precio de 5.600 reales. Tenía que estar terminado para el Lunes Santo del año siguiente ${ }^{32}$.

En un sentido más próximo a la arquitectura de retablos, se encontrarían otras obras desaparecidas, como son un sagrario para el monumento de la parroquia de Santiago (1687) y otro monumento para el convento de la Concepción $(1697)^{33}$.

\section{Aproximación a su estilo}

Por desgracia, todas las piezas «menores» que acabamos de citar no han llegado hasta nosotros. En cuanto a los retablos, solo podemos contar con los tres que se sabe que tallan para la iglesia del convento del Espíritu Santo entre 1677 y 1691. No obstante, de ellos solo uno se conservaba hasta hace unos años en su estado original pues los otros dos fueron rehechos con mayor o menor intensidad según el gusto rococó de la segunda mitad del XVIII, si bien poseen restos que pueden fecharse también hacia los años citados. Por ello, existe la fundamentada posibilidad de ser identificados con los realizados por nuestros artistas. En la actualidad, tras el reciente cierre de este cenobio han sido desgraciadamente desmontados de sus emplazamientos y se enfrentan a un futuro incierto. Por fortuna, podemos aportar en este artículo fotografías realizadas antes de su retirada. A estas obras habría que sumar, aunque con algunas reservas, un retablo hoy conservado en la antesacristía de la iglesia de la Victoria, también muy transformado en época rococó, que se podría identificar con el que hicieron para la hermandad de la Soledad en 1692, y el actual retablo de san José de la catedral, pieza que hay que situar ya en el puro terreno de las atribuciones.

Por tanto, hay que reconocer que no es demasiado consistente la base con la que contamos para aproximarnos al estilo de estos artistas. En cualquier caso, no puede desdeñarse la influencia directa de otros maestros foráneos que trabajan en la ciudad, como Juan González de Herrera. De hecho, los retablos que pueden relacionarse con Fernando Delgado y su hermano creemos que muestran ciertos ecos de las obras de este destacado maestro del Cádiz del seiscientos, como se percibe en el empleo de columnas salomónicas, en la organización de las calles laterales, con hornacinas enmarcadas por serpenteantes molduras rematadas por frontones triangulares o en los áticos flanqueados por aletones de los que cuelgan guirnaldas de frutas y, en ocasiones, coronados por frontones curvos muy quebrados en diferentes planos. La talla, por lo general, no parece alcanzar, sin embargo, la carnosidad que admiramos en retablos de González de Herrera como los del crucero de la iglesia de Santiago de Cádiz (1674) ${ }^{34}$. Interesante es del mismo modo el empleo de arquitrabes, frontones y molduras de perfiles ondulantes, aspecto desarrollado ampliamente en dichos 
retablos gaditanos. Está documentado que el detalle de las cornisas ondeantes se incluyó en el hoy perdido de san Cristóbal de Jerez, que contratan nuestros artistas en 1680, y también aparece en el actual de san José de la Catedral. Es posible que detrás de estos pormenores haya cierta influencia, seguramente indirecta, del "orden salomónico entero» ideado por fray Juan Ricci35.

Retablos documentados y atribuidos

La primera obra documentada es el retablo de la capilla del Cristo de la Viga de la Colegial. El 9 de febrero de 1676 lo ajusta Fernando Delgado a favor del mayordomo, el hermano mayor y el sacristán de la capilla y del veinticuatro Pedro Eustaquio de Morales Maldonado. Figura Delgado en la correspondiente escritura en solitario y como «carpintero de lo blanco». La obra tenía que ser de borne y cedro y alcanzar todo el alto y ancho de dicha capilla. El precio sería de 1.875 ducados y el plazo de realización un año ${ }^{36}$. No se conserva. En 1742 se encargó a Agustín de Medina y Flores uno nuevo, el actual, que con posterioridad se trasladó a la nueva iglesia, hoy catedral ${ }^{37}$.

Al año siguiente Delgado contrata el retablo del Espíritu Santo de la iglesia del convento del Espíritu Santo. El 29 de agosto de 1677 otorga la escritura de obligación a favor de sor María de Reina, monja profesa del convento. Se especifica que sería de pino, que su valor alcanzaría los 3.150 reales y que estaría terminado en ocho meses ${ }^{38}$.

Se trata del primero de los tres retablos concertados durante las tres últimas décadas del seiscientos para el templo de ese cenobio de monjas dominicas. Una iglesia que conservó hasta su cierre un retablo en el lado de la epístola dedicado a la Santísima Trinidad que nos decantamos por pensar que en origen fue el del Espíritu Santo contratado por estos retablistas en 1677. Tal vez fuera modificado un siglo más tarde para añadirle las figuras de Jesucristo y Dios Padre. Era de un único cuerpo, antecedido por un banco con un nicho central, y dividido en tres calles mediante pilastras toscanas cajeadas. En medio una gran hornacina, adelantada y de diseño rococó, con un altorrelieve de la Trinidad, contemporáneo a la transformación del retablo y vinculable a la gubia de Jacome Vacaro o su círculo ${ }^{39}$. En los laterales dos pequeños nichos con dos santos, uno en cada lado,

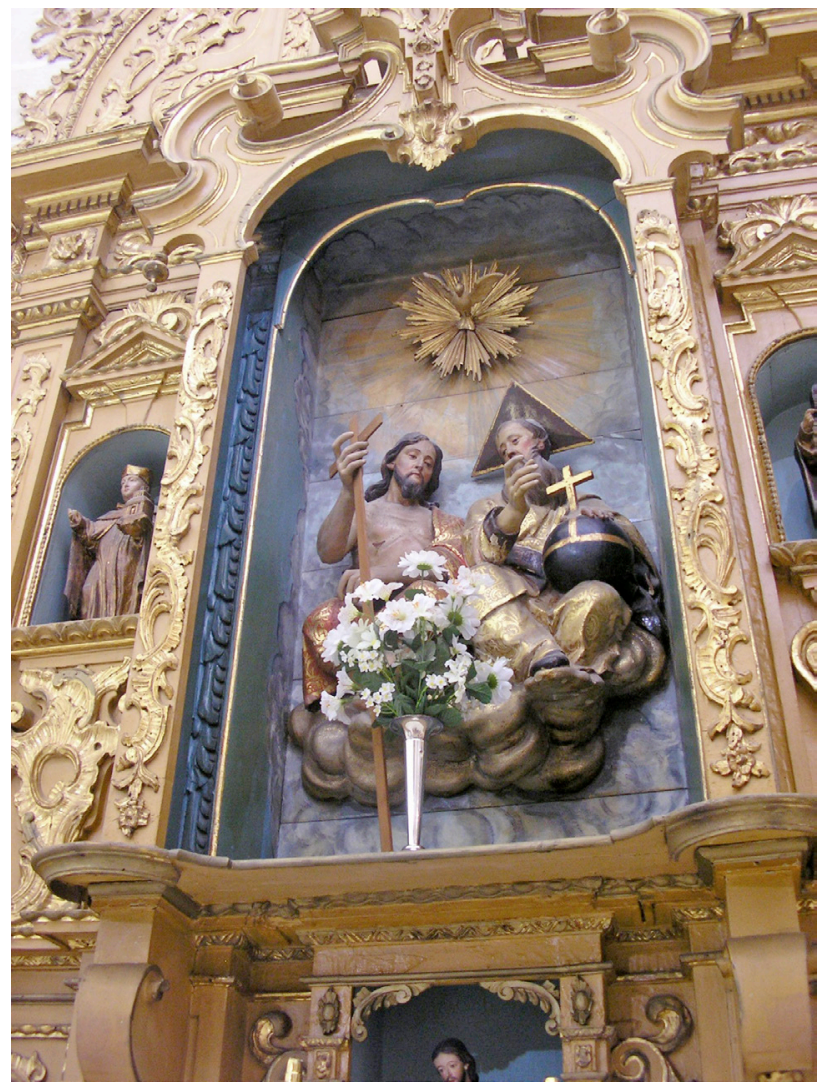

1. Anónimo, Retablo de la Santísima Trinidad de la iglesia del Espíritu Santo de Jerez de la Frontera, detalle, segunda mitad del siglo XVIII con elementos reaprovechados de un retablo realizado por Fernando Delgado y Bernardo Martín de la Guardia en 1677

que parecen haberse incorporado al altar en tiempos modernos. De hecho, en un inventario efectuado en 1836 con motivo de la desamortización describe el retablo así: «Es de talla, dorado y pintado. En el centro dentro se halla de relieve la Santísima Trinidad y a los colaterales dos nichos muy pequeños con dos angelitos ${ }^{40}$. El remate presentaba una silueta semicircular.

En general, perduraba, aunque recubierta de rocallas, la mayor parte de su estructura primigenia. De este modo, las calles laterales poseían hornacinas coronadas por frontones rectos que terminaban en molduras de perfiles ondeantes, las cuales vemos también en el banco y el arquitrabe superior. Quedaban en el friso también tarjas y florones de talla poco voluminosa. En el remate se observaban sendos aletones avolutados [1]. 


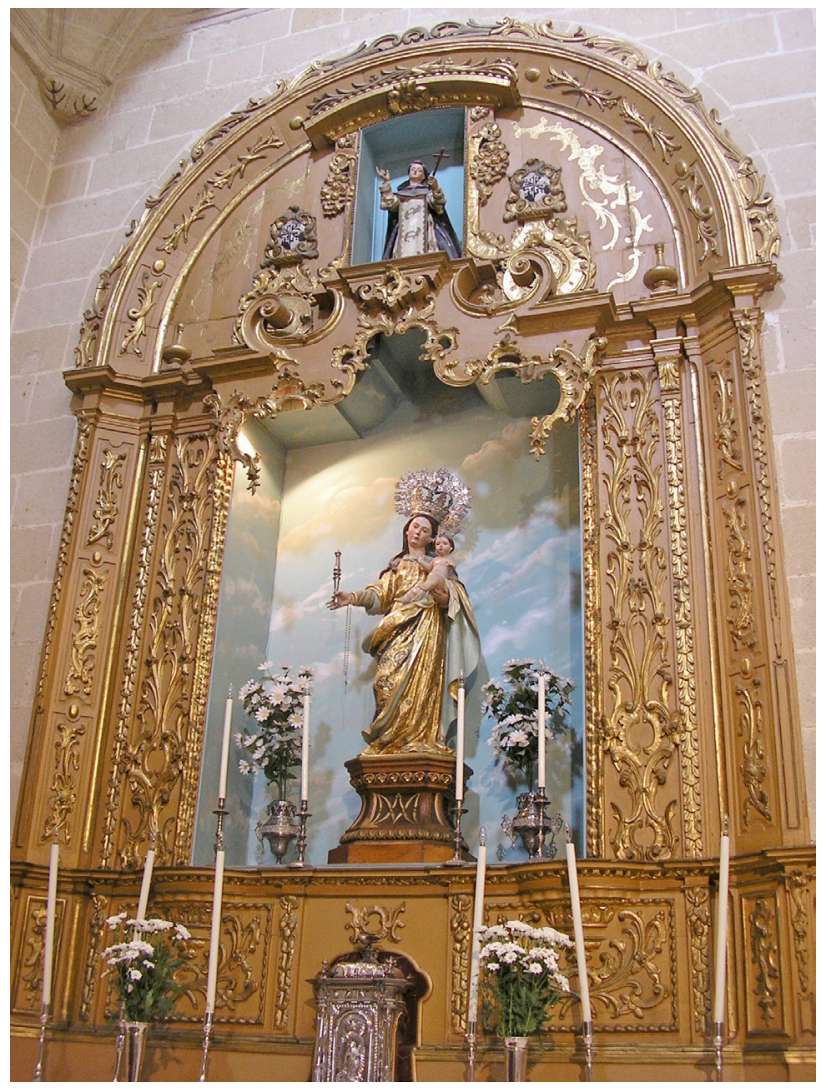

2. Anónimo, Retablo de la Virgen del Rosario de la iglesia del Espíritu Santo de Jerez de la Frontera, segunda mitad del siglo XVIII con elementos reaprovechados de un retablo realizado por Fernando Delgado y Bernardo Martín de la Guardia en 1687

El 3 de febrero de 1680 fue contratado el retablo mayor del convento de San Cristóbal ${ }^{41}$. Ahora son los dos hermanos los que otorgan la escritura, obligándose a hacerlo a favor de la priora sor Inés María Dávila y de Manuel Francisco de Zurita y Haro Cabeza de Vaca, caballero de la orden de Alcántara, Señor de Villar de Saz y veinticuatro perpetuo de Jerez. Debía ocupar todo el testero del altar mayor y realizarse su estructura en borne y «lo que fuere sobrepuesto, cornisas y molduras» en cedro. El precio se fijó en 30.500 reales. Se ejecutaría conforme a una planta o diseño al que se le hacen una serie de adiciones que son indicadas en la escritura. Estos añadidos consistirían, en primer lugar, en dotar al sagrario de cuatro columnas salomónicas «con sus parrones", siguiendo el mismo modelo de los soportes del «nicho de Nuestra Señora». Asimismo, se cambiarían por columnas salomónicas las pilastras grandes del segundo cuerpo «según las del cuerpo baxo», se agregaría una paloma del Espíritu Santo a la tarja sobre el nicho de la Virgen y una corona con dos palmas a la que sirve de remate al retablo, se incluirían en los fondos de los demás nichos tablas para colocar sobre ellos lienzos, se pondrían delante de los «arbotantes» que están sobre el banquillo del segundo cuerpo dos escudos de armas, el de los Zuritas y el de los Haro, como patronos del convento, y se tallaría la repisa o basa sobre la que iría la Virgen. Por último, como ya adelantamos al hablar del estilo de este taller, un aspecto digno de resaltarse es que se establece que se cambiarían todas las cornisas y molduras «llanas» por otras de perfil «ondeado».

No sabemos si llegó a materializarse este encargo. En 1723 Francisco Camacho se hace cargo de la ejecución de un sagrario y un camarín nuevos, por lo que quizás haya que admitir la existencia de un retablo antiguo que en esa fecha es modernizado ${ }^{42}$. No obstante, la iconografía no concuerda con la del reflejado en el inventario desamortizador del convento fechado en 1837, que lo describe como un retablo de madera de talla dorada con la imagen de san Cristóbal en el camarín, a los lados «dos efigies de talla» de san Pedro y san Pablo y rematando el conjunto un crucificado de unas dos varas de alto ${ }^{43}$. Debió de desaparecer en 1868, momento en el que se derriba el convento ${ }^{44}$.

El 15 de diciembre de 1686 se encargan de la realización del retablo de san Pedro Nolasco de la iglesia del convento de la Merced, que se situaría en un lateral de su capilla mayor. En esta ocasión, Delgado y Martín de la Guardia aparecen como «maestros de escultura». Se obligaron a hacerlo por 1.500 reales y en un plazo de unos tres meses. Con posterioridad, en 1702, y aprovechando la realización de otro para san Ramón Nonato, con destino al lado contrario del mismo espacio, parece que fue completado o sufrió una serie de transformaciones para igualarlo a este último, llevando a cabo ambos trabajos José Antonio Gijón ${ }^{45}$. En la actualidad no se conserva.

El retablo del Santo Cristo de la iglesia del convento del Espíritu Santo, que fue costeado por María de Lara, monja profesa del propio convento, se concierta el 10 de enero de 1687. Se hizo en madera de pino ${ }^{46}$. Pensamos que debió de ocupar el lugar del altar que últimamente se situaba los pies del lado del evangelio, presidido por una imagen de la Virgen del Rosario ${ }^{47}$. De todos los que estamos comentando de la iglesia del Espíritu Santo era el que más 
transformado estaba, por lo que hay que considerarlo obra nueva con elementos reaprovechados anteriores. Los más evidentes son los que aparecen en torno al hueco central del remate, como bien muestran la cornisa que la cierra y los aletones que la flanquea, de características próximas al vecino retablo de santo Domingo. La forma y anchura de la hornacina del primer cuerpo hace pensar en un retablo para acoger las tres imágenes de un Calvario, como demuestra el inventario de 1836, que se refiere a él como «Retablo de talla dorado y pintado que es el sagrario. En su centro se halla la efigie del crucificado, nuestra Señora y San Juan» ${ }^{48}$. Es por ello que creemos que estos restos pueden proceder del retablo levantado en 1687 para el citado altar del Santo Cristo, que debió de ocupar el mismo lugar que este [2].

Finalmente, el 24 de mayo de 1691 Andrés Dávila, caballero de la orden de Calatrava, les encomienda hacer otro para un altar del lado del evangelio del mismo templo ${ }^{49}$. Pensamos que debe identificarse con el que últimamente estaba dedicado a santo Domingo de Guzmán, el cual al igual que este se asentaba sobre el mismo muro y que ya fue atribuido a Delgado y Martín de la Guardia por parte de Pomar Rodil y Mariscal Rodríguez tomando como base la documentación de los trabajos para este cenobio ${ }^{50}$. Es el único que ha llegado hasta nosotros manteniendo su morfología original. Por el inventario de 1836 con motivo de la desamortización puede constatarse que su primitivo titular era san Vicente Ferrer. Se le describe como «de talla pintado y dorado con la efigie en su centro de San Vicente Ferrer. A los colaterales, dos lienzos como de vara y media de alto y tercia de ancho con San José y otro santo. En la parte superior un cuadro como de media vara con su cristal que representa la efigie de nuestra Señora de Belen». Se aclara igualmente que por esa fecha el retablo había pasado a ser propiedad de los marqueses de Casa Vargas ${ }^{51}$.

Es uno de los ejemplares de mayor interés entre los retablos salomónicos jerezanos. Sigue la estructura habitual de banco, un solo cuerpo de tres calles y ático. Tarjas y gruesos roleos vegetales son la ornamentación principal. La hornacina central se remata por una moldura mixtilínea que acoge en el centro una plástica cartela con el anagrama de Jesús estofado. Las columnas son de seis espiras y enmarcan unas calles laterales que ostentan pinturas con san José y santa Catalina. Sobre estas últimas, dos frontones rectos rotos y superpuestos. El friso tiene la peculiaridad de

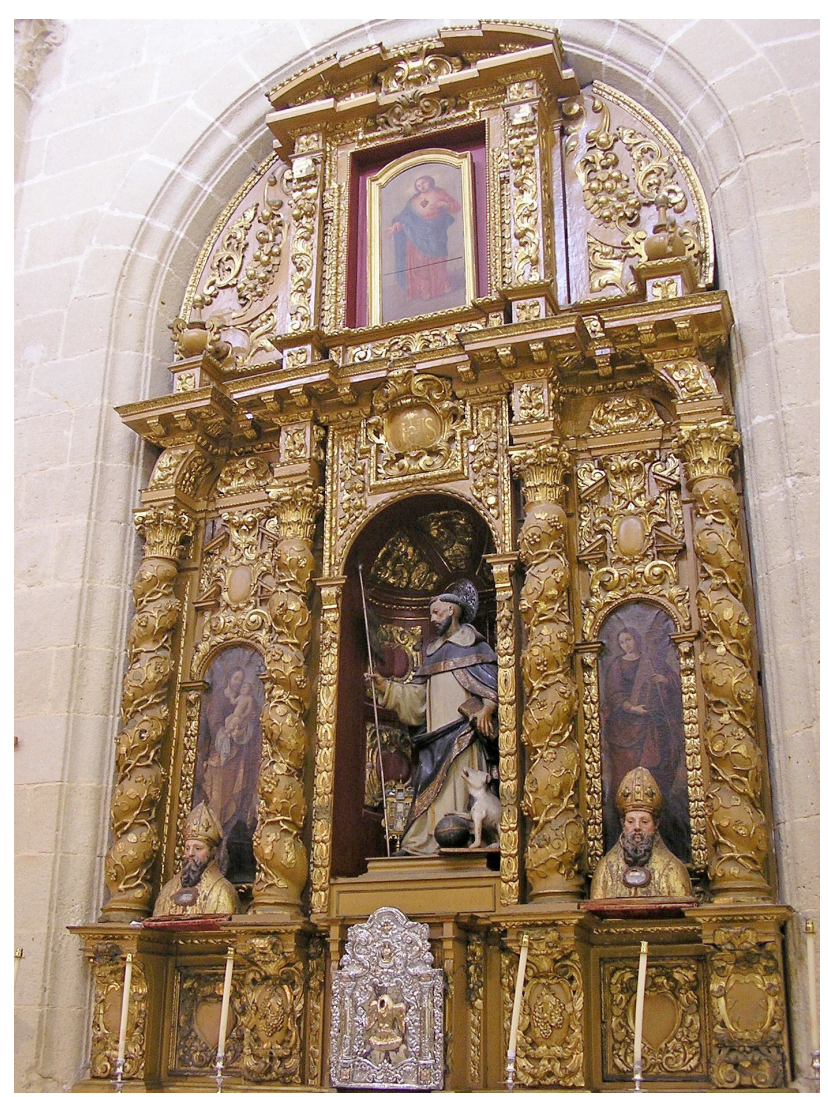

3. Fernando Delgado y Bernardo Martín de la Guardia, Retablo de Santo Domingo de la iglesia del Espíritu Santo de Jerez de la Frontera, 1691

curvarse lateralmente en los extremos, solución excepcional que solo hemos localizado en Jerez en esta obra. El ático se compone de un edículo que acogía últimamente un cuadro representando al Sagrado Corazón de Jesús. Unas pilastras con sinuosa decoración vegetal sostienen un frontón curvo y quebrado en varios planos. Al igual que el arquitrabe inferior, dicho frontón acaba en moldura levemente ondeada y gallonada por múltiples y menudos lóbulos. A ambos lados, aletones acabados en volutas de los que penden guirnaldas frutales. La policromía que muestra debió de aplicarse al tiempo que se reformaron los otros dos retablos de la misma iglesia, alrededor del último tercio del XVIII, ya que todos muestran su talla dorada y los fondos con el mismo tono ocre [3].

El retablo de la Virgen de la Soledad del convento de la Victoria se proyectó para el altar mayor de la capilla 


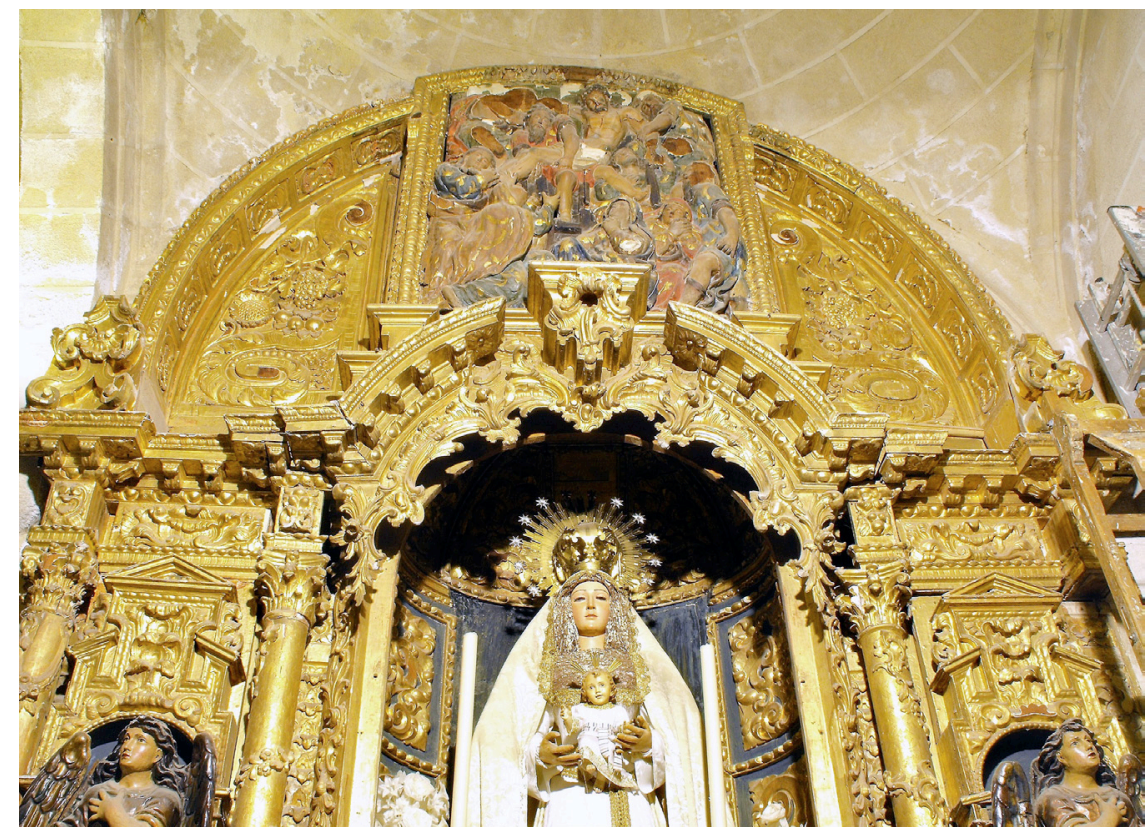

4. Fernando Delgado y Bernardo Martín de la Guardia (atribuido), Retablo de la antesacristía de la iglesia de la Victoria de Jerez de la Frontera, detalle, ¿1692?

que su hermandad poseía en este monasterio. El correspondiente contrato, que firma Delgado el 27 de febrero de 1692, habla de hacerlo en cedro y borne según una «planta» que habían dibujado previamente, aunque «acrecentando la glosura (sic) y niños que le corresponden». Se ejecutaría por 6.000 reales y en un año de plazo ${ }^{52}$. No sabemos si se llegó a hacer o terminar. En 1715 tenemos constancia de que se estaba haciendo otro retablo por parte de esta cofradía ${ }^{53}$. Mucho después, entre 1788 y 1790, hemos podido averiguar que se dora el altar de esta imagen por Julián de Padilla, si bien no podemos confirmar si se trata de la misma pieza o de otra nueva ${ }^{54}$. En cualquier caso, resulta sugerente la existencia en la actual antesacristía de la iglesia de la Victoria de un retablo que podemos fechar a finales del siglo XVII y que podría vincularse con estos maestros. Se compone de un banco con sagrario central con dos pequeñas columnas salomónicas, un solo cuerpo de tres calles, articulado por cuatro columnas corintias, y ático semicircular en forma de arcosolio, que la documentación de la época llama «bolsura» ${ }^{55}$. Hay que incidir en que está reformado y dorado en la segunda mitad del setecientos, momento en el que se le sustituirían los soportes prin- cipales, que son ahora de fuste liso con decoración rococó, se cambió la embocadura de la hornacina central y se añadirían la mesa de altar y rocallas en algunas zonas. Las partes originales están, en cambio, en una línea muy próxima a lo visto en el convento del Espíritu Santo, como se observa en el uso de frontones rectos sobre las hornacinas laterales, el arquitrabe ondeante o los avolutados cartabones con guirnaldas del remate. A estos motivos se unen otros elementos propios de la época, como niños atlantes bajo las columnas, que también se citan en el referido contrato de 1692, y la ruptura curva del entablamento en la calle central. La iconografía primitiva que aún conserva, un relieve del Descendimiento en el cuerpo superior y ángeles mancebos de gesto lloroso en el sagrario, nos habla del carácter pasionista del retablo, idóneo para cobijar la imagen de una Dolorosa [4].

La última obra de relevancia que conocemos de este taller es el retablo del Santo Crucifijo de la parroquia de San Miguel. La escritura de obligación se fecha el 25 de julio de 1696. Fue concebido para estar articulado por cuatro columnas con figuras de niños repartidos debajo y encima de las mismas y un remate con una imagen de san Miguel 
dentro de una hornacina entre dos cartelas. Se estableció un precio de 7.000 reales y un plazo de realización de tres años $^{56}$. Con todo, tenemos constancia de que aún en 1705 no se había concluido ${ }^{57}$. Debió de perderse en 1750, cuando la hermandad encarga uno nuevo a Matías José Navarro58.

No podemos acabar sin hacer un comentario del antiguo retablo de la Concepción de la catedral, hoy ocupado por una imagen de san José59. Es otra de las muestras más interesantes que se conservan en Jerez de la retablística de la segunda mitad del siglo XVII. La atribución corresponde también a Pomar y Mariscal, quienes de nuevo se basan en la constancia del trabajo de estos retablistas para la antigua Colegial, para la que sabemos que harían un retablo para el Cristo de la Viga ya en $1676^{60}$. No obstante, hay que hacer constar que existe una teoría anterior de De los Ríos Martínez identificando este retablo con uno donado en 1652 por el canónigo magistral Alonso Caballero de los Olivos y considerándolo obra del círculo de Alejandro de Saavedra ${ }^{61}$. Lo único seguro es que procede de la antigua iglesia Colegial, edificio anterior al actual primer templo jerezano y que fue colocado en el lugar que hoy ocupa con motivo de su inauguración en $1778^{62}$. En ese momento debió de reformarse la hornacina central, se abrió un pequeño hueco en el centro del banco y se añadiría la mesa de altar, además de aplicarse un nuevo dorado y policromía, todo ello según el lenguaje rococó.

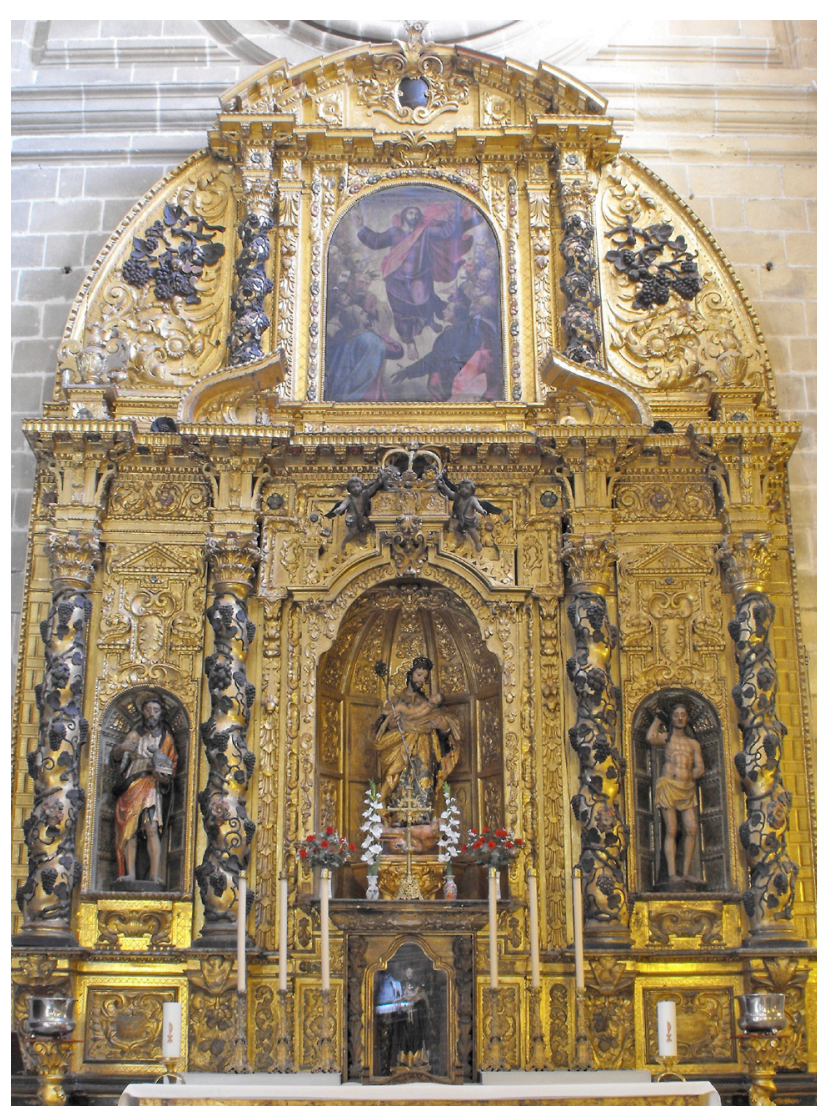

5. Fernando Delgado y Bernardo Martín de la Guardia (atribuido), Retablo de San José de la Catedral de Jerez de la Frontera, último cuarto del siglo XVII ca.
6. Fernando Delgado y Bernardo Martín de la Guardia (atribuido), Retablo de San José de la Catedral de Jerez de la Frontera, detalle del entablamento, último cuarto del siglo XVII ca.

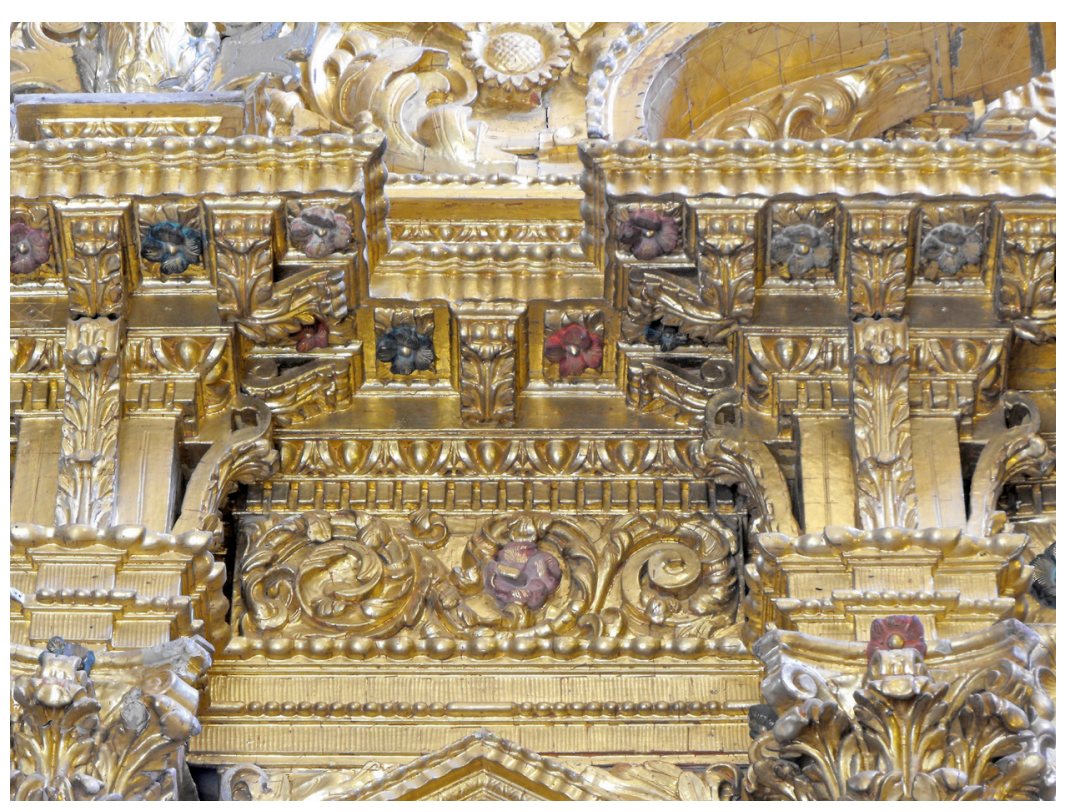


Consta de un único cuerpo estructurado en tres calles separadas por cuatro columnas salomónicas. En las calles laterales se hallan hornacinas con tallas de san Juan Bautista y san Sebastián, obras muy anteriores al retablo63. El ático es semicircular e integra una pintura con un lienzo de la Ascensión, que es flanqueado por otras dos columnas de fuste salomónico que soportan un frontón curvo y quebrado en distintos planos, que remata todo el conjunto. El diseño compositivo y el apartado decorativo están muy cercanos a los vistos en el retablo de Santo Domingo del Espíritu Santo, como se observa en el tipo de enmarque de los nichos laterales o las tarjas que se disponen en el banco. Las columnas salomónicas de cinco espiras o los fragmentos de frontones contracurvos y de trayectoria ascendente que se observan en la cornisa superior nos traen a la memoria retablos del foco artístico gaditano de este periodo, especialmente, los de Juan González de Herrera. En este mismo sentido, hay que hablar de la llamativa cornisa ondeante, que se encuentra en los retablos que dicho artista hace para el crucero de la iglesia de Santiago de Cádiz pero que de manera significativa también sería usada en el retablo desaparecido que Delgado y Martín de la Guardia harían para el convento jerezano de San Cristóbal [5 y 6].

\section{Notas}

1 MORENO ARANA, José Manuel, El retablo en Jerez de la Frontera durante el siglo XVIII, Sevilla, Secretariado de Publicaciones de la Universidad de Sevilla, 2014, pp. 195-238.

2 JÁCOME GONZÁLEZ, José y ANTÓN PORTILLO, Jesús, «Apuntes histórico-artísticos de Jerez de la Frontera en los siglos XVI-XVIII (2. serie)», Revista de Historia de Jerez, n. ${ }^{\circ}$ 7, 2001, pp. 111-112 y 114. JÁCOME GONZÁLEZ, José y ANTÓN PORTILLO, Jesús, "Apuntes histórico-artísticos de Jerez de la Frontera en los siglos XVI-XVIII (3ª serie)», Revista de Historia de Jerez, n. ${ }^{\circ}$ 8, 2002, pp. 117-118.

3 POMAR RODIL, Pablo Javier y MARISCAL RODRÍGUEZ, Miguel Ángel: Jerez. Guía artística y monumental, Madrid, Sílex, 2004 , pp. 123 y 145.

4 Una visión global sobre la realización de estos dos retablos puede consultarse en: DE LOS RíOS MARTíNEZ, Esperanza, José de Arce y la escultura jerezana de su tiempo: 1637-1650, Cádiz, Diputación de Cádiz, 1991, pp. 49-67 y 71-78.

5 DABRIO GONZÁLEZ, María Teresa, Los Ribas. Un taller andaluz de escultura del siglo XVII, Córdoba, 1985 , pp. 418 y 620.

6 HORMIGO SÁNCHEZ, Enrique, Vida y obra de Francisco de Villegas. Escultor, retablista y ensamblador, Cádiz, 2002 pp. 37 y $42-43$.

7 JÁCOME GONZÁLEZ, J. y ANTÓN PORTILLO, J., "Apuntes histórico-artísticos de Jerez de la Frontera en el siglo XVIl», Revista de Historia de Jerez, n. ${ }^{6}$, 2000, pp. 188 y «Apuntes... (2. ${ }^{a}$ serie)», p. 115.

8 W. AA., Intramuros: La Cartuja de Nuestra Señora de la Defensión, Jerez de la Frontera, Publicaciones del Sur, 2003, pp. 38-39.

9 MORENO ARANA, El Retablo..., pp. 197-198.

10 Un completo estudio sobre este artista en: ibid., pp. 205-226.

11 Sobre Rey ver: ibid., pp. 226-238.

12 Sobre el asunto de la organización gremial de los retablistas jerezanos y sus pretensiones de ascenso social ver: Ibid., pp. 33-37 y 125-148.

13 SANCHO DE SOPRANIS, Hipólito, «Papeletas para una serie de artistas regionales (segunda serie)», Guión, n. ${ }^{\circ} 27$, p. 13. BARROSO VÁZQUEZ, María Dolores, «Arquitectura efímera en el Jerez del Seiscientos: Antón Martín Calafate y Lorenzo de Vargas», Trivium, n. 5, 1993, pp. 372-378. JÁCOME GONZÁLEZ y ANTÓN PORTILLO, «Apuntes...», pp. 189-190; «Apuntes... (2. ${ }^{a}$ serie)», p. 116 y «Apuntes... (3. ${ }^{a}$ serie)», p. 125.

14 Para no alargar innecesariamente estas notas aportamos la primera y última referencia que hemos localizado sobre él en los padrones parroquiales: Archivo Histórico Diocesano de Jerez de la Frontera (A.H.D.J.F.), Fondo Parroquial, Parroquia de San Miguel, Padrones, distrito 3. ${ }^{\circ}$ años 1659 al 1661 , año 1659 , f. 63v. Ibid., años 1682 al 1686, año 1685, f. 85v. A través de ellos sabemos el nombre de su mujer, Beatriz Velázquez.

15 En caso de ser el mismo que se dora entre 1706 y 1707 y que fue identificado en: MORENO ARANA, J. M., La Policromía en Jerez de la Frontera durante el siglo XVIII, Sevilla, Universidad de Sevilla, 2010, pp. 128-129.

16 MORENO ARANA, El Retablo..., pp. 196-197.

17 A.H.D.J.F., Fondo Parroquial, Parroquia de San Miguel, Matrimonios, Libro 9 (años 1676 al 1683), f. 145.

18 El no conocer los nombres de sus padres dificulta averiguar cuándo nacieron. En todo caso, en la parroquia de San Miguel, en cuya collación viven desde las fechas más tempranas, conocemos el bautismo de dos niños de padres no conocidos con los nombres de Fernando (17 de mayo de 1650$)$ y Bernardo (28 de agosto de 1653): A.H.D.J.F., Fondo Parroquial, Parroquia de San Miguel, Bautismos, Libro 23 (años 1647 al 1656 ), ff. 189v y 368.

19 A.H.D.J.F., Fondo Parroquial, Parroquia de San Miguel, Padrones, distrito 3. años 1659 al 1661, año 1659, f. 63v; año 1660, f. 53; año 1661, f. 55. Aparecen junto a ellos desde el principio y durante muchos años otras dos mujeres, cuya vinculación con ellos ignoramos: María de Astorga y Antonia de Argumedo.

20 Aparecen recogidos por las mismas fechas en los padrones parroquiales. Como ejemplo ver: A.H.D.J.F., Fondo Parroquial, Parroquia de San Miguel, Padrones, distrito $3^{\circ}$, años 1659 al 1661, año 1659, f. 53v.

21 Archivo de Protocolos Notariales de Jerez de la Frontera (A.P.N.J.F.), legajo 1981, oficio III, escribano Juan Cordero de Molina, año 1677 , f. 20.

22 A.H.D.J.F., Fondo Parroquial, Parroquia de San Miguel, Padrones, distrito 3. ${ }^{\circ}$, años 1662 al 1665, año 1662, f. 56; año 1663, f. 59v; año 1664, f. 50; año 1665, f. 60. Ibid., años 1682 al 1686, año 1682, f. 66; año 1683, f. 70; año 1684, f. 79; año 1685, f. 82; año 1686, f. 67. Ibid., años 1666 al 1669, año 1666, f. 60; año 1667, f. 57v; año 1668, f. 57v; año 1669, f. 56. Ibid., años 1670 al 1674, año 1670, f. 53v; año 1671, f. 59; año 1672, f. 55; año 1673, f. 60; año 1674, f. 63. Ibid., años 1676 al 1682, año 1676, f. 64; año 1677, f. 73v; año 1678, f. 61v; año 1680, f. 61v; año 1681, f. 63. Ibid., años 1682 al 1686, año 1682, f. 66; año 1683, f. 70; año 1684, f. 79; año 1685, f. 82; año 1686, f. 67. Ibid., años 1687 al 1692, año 1687, f. 69; año 1688, f. 76; año 1689, f. 85; año 1690, f. 85; año 1691, f. 61v. Ibid., años 1694 al 1701, año 1694, f. 50; año 1695, f. 53; año 1696, f. 51v; año 1697, f. 53v; año 1698, f. 48; año 1699, f. 47v; año 1700, f. 57; año 1701, f. borrado. 
23 A.H.D.J.F., Fondo Parroquial, Parroquia de San Mateo, Matrimonios, Libro 4 y 5 (años 1668 a 1709), f. 58v. La velación tiene lugar el 20 de febrero de 1680: A.H.D.J., Fondo Parroquial, Parroquia de San Miguel, Matrimonios, Libro 9 (años 1676 a 1683), f. 145.

24 Todo lo anterior lo sabemos por su testamento. También por el de Manuela Francisca de Luna, otorgado el 29 de Junio de 1709 (A.P.N.J.F., tomo 2271 , oficio IX, escribano José Guerrero, año 1709, ff. 190-191).

25 A.P.N.J.F., tomo 2140, oficio IX, escribano Rodrigo Benítez, año 1694, ff. 234-235.

26 Hemos localizado la que creemos que es su partida de defunción, aunque hay que advertir que parece contener errores a la hora de nombrar al fallecido y a su viuda. En este sentido, concluimos que debe de ser el hombre vecino de la calle Larga llamado Fernando de la Guardia y esposo de Manuela Francisca de Lara que se enterró dicho día: A.H.D.J., Fondo Parroquial, Parroquia de San Miguel, Defunciones, Libro 6ºños 1690 al 1695), f. 169. En el padrón parroquial de 1695 su esposa ya es recogida, en efecto, como viuda.

27 JÁCOME GONZÁLEZ y ANTÓN PORTILLO, «Apuntes... (2. ${ }^{a}$ serie)», p. 111

28 A.H.D.J., Fondo Parroquial, Parroquia de San Miguel, Padrones de los años 1702 al 1709, año 1702, f. 54v; año 1703, f. 55; año 1704, f. 64; año 1705, f. 67; año 1706, f. 57; año 1707, f. 56; año 1708, f. 72; año 1709, f. 62v. En el de 1709 ya no figura viviendo en la casa familiar.

29 A.P.N.J.F., tomo 2244, oficio IX, escribano José Guerrero, año 1708, f. 217.

30 A.P.N.J.F., legajo 2091, oficio I, escribano Francisco Márquez Rendón, año 1689, f. 554.

31 JÁCOME GONZÁLEZ y ANTÓN PORTILLO, «Apuntes... (2. ${ }^{a}$ serie)», p. 111.

32 A.P.N.J.F., legajo 2150, oficio VI, escribano Francisco Márquez Arroyo, año 1695, ff. rotos.

33 JÁCOME GONZÁLEZ y ANTÓN PORTILLO, «Apuntes... (2. ${ }^{a}$ serie)», pp. 111-112.

34 Para la obra conservada de González de Herrera ver: HORMIGO SÁNCHEZ, Enrique, "El Retablista González de Herrera», El Periódico de la Bahía, 3 de noviembre de 1990, p. 13 y "Juan González de Herrera y su obra en la Iglesia de Santiago de Cádiz", Anales de la Real Academia de Bellas Artes de Cádiz, n. ${ }^{\circ} 12,1994$, pp. 121-130.

35 RAMíREZ, Juan Antonio, «Guarino Guarini, Fray Juan Ricci y el orden salomónico entero», Goya, n. 160, Madrid, 1981, pp. 202-211. RICCI DE GUEVARA, Juan Andrés, La pintura sabia, edición a cargo de Fernando Marías y Felipe Pereda, Madrid, 2002.

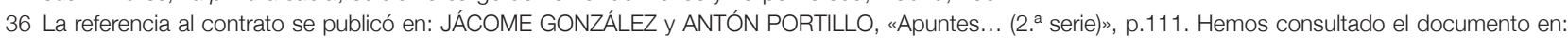
A.P.N.J.F., legajo 1949, oficio XIII, escribanos Baltasar de Torres y Francisco Ignacio de Magallanes, año 1676, ff. 36-37.

37 ALONSO DE LA SIERRA FERNÁNDEZ, L., "El retablista Agustín Medina y Flores. Aproximación al estudio de su obra», Revista de Historia de Jerez, n. 8 , 2002, pp. 142-145.

38 A.P.N.J.F., legajo 1981, oficio III, escribano Juan Cordero de Molina, año 1677, f. 183. Documento citado en: JÁCOME GONZÁLEZ y ANTÓN PORTILLO, "Apuntes... (2. ${ }^{a}$ serie)», p. 111.

39 MORENO ARANA, J. M., «La impronta genovesa en la escultura jerezana de la segunda mitad del siglo XVIIl», Revista de Historia de Jerez, n. ^16-17, 2014, p. 190.

40 Archivo Histórico Provincial de Cádiz (A.H.P.C.), Sección Hacienda, Desamortización, caja 1237, expediente 4.

41 A.P.N.J.F., legajo 2012, oficio XV, escribano Juan Caballero de Sanabria, año 1680, ff. 62-63. La referencia al documento fue publicada, aunque sin detallar su contenido, en: JÁCOME GONZÁLEZ y ANTÓN PORTILLO, «Apuntes... (2. ${ }^{\text {a }}$ serie)», p. 111.

42 ALONSO DE LA SIERRA FERNÁNDEZ, Lorenzo y HERRERA GARCÍA, Francisco J., "Aproximación a la escultura jerezana del siglo XVIII: Francisco Camacho de Mendoza", Atrio. Revista de historia del arte, n. ${ }^{\circ}$ 5, 1993, p. 29.

43 A.H.P.C, Sección Hacienda, Desamortización, caja 1237, expediente 13, s/f. En la descripción se especifica que la imagen del santo titular era propiedad de Juan David Gordon y su esposa.

44 MUÑOZ Y GÓMEZ, Agustín, Noticia Histórica de las Calles y Plazas de Xerez de la Frontera, Imprenta de «El Guadalete», 1903, p. 87.

45 JÁCOME GONZÁLEZ y ANTÓN PORTILLO, "Apuntes... (3. a serie)», p. 118 y Entre legajos. Fuentes documentales para la historia del arte en Jerez de la Frontera, 2009, pp. 40-48.

46 JÁCOME GONZÁLEZ y ANTÓN PORTILLO, «Apuntes... (3. ${ }^{a}$ serie)», p. 118.

47 Esta imagen mariana, al igual que el Santo Domingo del retablo al que a continuación haremos referencia, proceden del desaparecido retablo mayor, que concierta en 1690 Francisco Antonio de Soto. Se han atribuido a Ignacio López: MORENO ARANA, José Manuel, El retablo..., pp. $220-221$.

48 A.H.P.C, Sección Hacienda, Desamortización, caja 1237, expediente 4. Se informa asimismo que las esculturas, cuyo paradero desconocemos, fueron costeadas por la priora Sor Joaquina Jaimes y las Madres Jiménez.

49 JÁCOME GONZÁLEZ y ANTÓN PORTILLO, «Apuntes... (3. ${ }^{a}$ serie)», p. 118.

50 POMAR RODIL y MARISCAL RODRÍGUEZ, Guía..., p. 145.

51 A.H.P.C, Sección Hacienda, Desamortización, caja 1237, expediente 4, s/f.

52 A.P.N.J.F., legajo 2120, oficio VI, escribano Francisco Márquez Arroyo, año 1692, f. 65. Documento citado en: JÁCOME GONZÁLEZ y ANTÓN PORTILLO, "Apuntes... (2. ${ }^{a}$ serie)", p. 111.

53 Archivo General del Arzobispado de Sevilla (A.G.A.S.), fondo Arzobispal, sección Gobierno, serie Libros de Visitas Pastorales, legajo 05187, f. 144v.

54 Archivo Histórico Nacional, Sección Clero Secular Regular, libro 1980, f. 3.

55 Este término aparece también, por ejemplo, en el contrato del retablo de Ánimas de la Prioral de El Puerto, que concierta Alonso de Morales en 1680 (MORENO ARANA, J. M., "La difusión del barroquismo sevillano en El Puerto y su entorno: Ignacio López y Alonso de Morales», Revista de Historia de El Puerto, n. ${ }^{\circ} 37,2006$, pp. 47-80).

56 JÁCOME GONZÁLEZ y ANTÓN PORTILLO, «Apuntes... (3. ${ }^{a}$ serie)», p. 118.

57 A.G.A.S., fondo Arzobispal, sección Gobierno, serie Libros de Visitas Pastorales, legajo 05170, ff. 32-33.

58 MERINO ARANDA, José Miguel, «La Capilla del Santo Crucifijo en San Miguel», Jerez en Semana Santa, n. ${ }^{\circ} 6,2002$, pp. $337-348$.

59 Últimamente y hasta hace poco tiempo estuvo presidido por una imagen moderna de San Juan Grande.

60 POMAR RODIL y MARISCAL RODRÍGUEZ, Guía..., p. 123.

61 RíOS MARTÍNEZ, José de Arce..., pp. 108-110.

62 REPETTO BETES, José Luis, La obra del templo de la Colegial de Jerez de la Frontera, Cádiz, Diputación Provincial de Cádiz, 1978, p. 157.

63 Son 1592 y obra del escultor Hernando Lamberto (JÁCOME GONZÁLEZ, J. y ANTÓN PORTILLO, J., «Aproximación a la vida y obra del entallador y escultor flamenco Hernando Lamberto en Jerez de la Frontera”, Revista de Historia de Jerez, n. ${ }^{9}$, 2003, pp. 63-65). 